\title{
VI. Some radioactive properties of uranium
}

\section{T. Godlewski Ph.D.}

To cite this article: T. Godlewski Ph.D. (1905) VI. Some radioactive properties of uranium , Philosophical Magazine Series 6, 10:55, 45-60, DOI: 10.1080/14786440509463343

To link to this article: http://dx.doi.org/10.1080/14786440509463343

曲 Published online: 16 Apr 2009.

Submit your article to this journal 전

Џll Article views: 2

Q View related articles ¿

4 Citing articles: 4 View citing articles $\square$ 
The $\beta$ rays of actinium are completely distinct in their character from the $\beta$ rays emitted by the other radio-elements, inasmuch as they are completely homogeneous. This fact was established by the measurements of absorption of $\beta$ rays in passing through solid bodies. The activity measured by $\beta$ rays decreased strictly according to an exponential law with the thickness of matter traversed. The equation $I=I_{0} e^{-\lambda d}$, where $d$ is the thickness, was applicable even in the case when $I$ was less than 1 per cent. of its original value.

The $\beta$ rays from actinium differ also from the $\beta$ rays of other radioactive elements in the absolute value of the absorption constant $\lambda$, which is about 2.5 times as great with actinium as with uranium. Thus the $\beta$ rays of actinium have less than half the penetrating power of those emitted by any other radio-element.

The existence of the $\gamma$ rays from actinium was also distinctly proved. The absorption measurements showed that the $\gamma$ rays of actinium are fairly homogeneous, and their penetrating power was only about one quarter of that observed for the rays from radium. A more complete account of these investigations will be published later on.

In conclusion it is my most pleasant duty to express my deepest gratitude to Prof. Rutherford for suggesting these investigations, for his kindness in the advice he has so freely given to me, and for placing at my disposal all the plentiful resources of his laboratory at MeGill University.

McGill University, Physies Building, February 24, 1905 .

VI. Sone Radioactive Properties of Uranium. By'T. Godlewski, Ph.ll. (Cracow)*

\section{The Discovery of $\mathrm{Ur} X$.}

J 1900 Sir William Crookes $\dagger$ showed that it is possible to $\mathcal{L}$ separate from uranium by a single chemical operation a small amount of radioactive substance to which he gave the name UrX. This substance was, weight for weight, many hundred times more active photographically than the uranium from which it had been separated. The uranim deprived of this substance was almost inactive.

Similar results were afterwards observed by Becquerel $\ddagger$,

* Communicated by Prof. E. Rutherford, F.R.S. Presented before the Academy of Sciences in Cracow at the sitting of 9th of May, 1905.

† Crookes, Proc. Roy. Soc. lxvi. p. 409 (1900).

† Becquerel, C.R. cxxxi. p. 137 (1900); cxxxiii. p. 977 (1901). 
who also noted the important fact that uranium recovered its activity with the time, while the activity of the separated substance decayed. This phenomenon was then quantitatively investigated by Soddy *, by Rutherford and Grier $\dagger$, and by Rutherford and Soddy $\neq$.

'These investigations proved that the activity of $\operatorname{UrX}$, when measured by $\beta$ rays, decayed with the time according to an exponential law, falling to half value in 22 days. In the same period uranium which, by removal of $\mathrm{UrX}$, was deprived of all its $\beta$ activity recovered it, and the recovery curve was complementary to the curve of decay of $\mathrm{UrX}$. From the point of view of the disintegration theory, this fact indicated that $\mathrm{UrX}$ is a successive product of uranium, and the change of $\mathrm{Ur}$ into its snccessive product was accompanied by the emission of $\beta$ particles.

\section{The Experiments of Meyer and Schweidler on Uranium.}

In $190 \pm$ Meyer and von Schweidler $\&$ repeated the quantitative measurements of Rutherford and Soddy with the difference, that while the latter used for separation of $\mathrm{UrX}$ the method of Becquerel, they made use of Croolies's method.

The aqueous solution of uranium nitrate was shaken with ethyl ether, and then the ether and water portions were separated from one another. The ether portion contained uranium nitrate deprived of $\mathrm{UrX}$, and the $\beta$ activity of this portion increased according to the theoretical curve, to half of its total value in 22 days. The uranium nitrate, however, when crystallized from the remaining water portion, lost its $\beta$ activity at a different rate, decaying to half value in 2 days instead of 22 days. This unusual fact, that the recovery and decay curves of a radioactive product were not complementary to one another, either pointed to the existence of a new product, or indicated some unknown radioactive phenomenon. In order to elucidate this question, Meyer and Schweidler started a series of investigations on the radioactive properties of uranium nitrate freshly crystallized from the water solutions. They substantiated the tact that uranium nitrate crystallized from the hot-water solutions in the form of compact plates exhibited a peculiar radionctive behaviour. The activity of these

* Soddy, Trans. Chem. Soc. lxxxi. p. 860 (1902).

+ Rutherford and Grier, Phil. Mag. Sept. 1902, p. 315.

\pm Rutherford and Soddy, Phil. Mag. April 1903, p. 411.

$\S$ Meyer and v. Schweidler, "Untersuchungen über radioaktive Substanzen, II. : Ueber die Strahlung des Uran." Sitzber. der Wiener Akad. Mathem.-naturwiss. Klasse, Bd. 113. Abt. II. a.pp. 1057-1079, Juli 1904. 
plates decayed in the first few days after crystallization to about half of its original value, reaching a minimum after four or five days, and then increased slowly for a very long time. The time in which the minimum was reached and the initial form of the curve were both dependent on the thickness of the plate. As regards the meaning of this phenomenon, the authors suggest two possibilities: either that there is a change in the activity itself, or that the absorption of the rays is modified by the physical alteration of the crystallized plates*.

Prof. Rutherford kindly suggested to me, that I should make some investigations to explain these phenoment.

\section{The Separation of UrX from Uranium by means of Fractional Crystallization.}

The experiments were first made in order to find out the conditions under which this first rapid decay of the $\beta$ activity of uranium is obtained.

As in the experiments of Mieyer and von Schweidler, equal weights of uranium nitrate $\dagger$ and water were taken, and this solution was shaken with an equal weight of ethyl ether. The ether solution was then carefully separated from the water solution, and both were evaporated to drymess. In the case of water solution, the evaporation was continued until eren the water of crystallization was driven off.

The $\alpha$ and $\beta$ activity of both portions were then measured.

The $\beta$ activity was measured by means of an electroscope $\ddagger$ of the type of C.T. R. Wilson ; the bottom of the electroseope was removed and replaced by aluminium foil $0.08 \mathrm{~mm}$. thick, which absorbed all the a rays.

The measurements showed that uranium nitrate from the aqueous solution which contained the excess of UrX, derived from the ether solution, lost the corresponding excess of its activity according to an exponential law with the time, falling to half value in 22 days. The ether portion, which was at first almost completely inactive, when measured by $\beta$

* "Bezüglich der Deutung dieses Verhaltens ist zunächst die Mïğlichlieit gegeben, dass es sich um Änderungen der $\Lambda$ ktivität selbst handelt, oder dass durch physilalische Zustandesänderungen der Kristallplatten ihr Absorptionsverinögen beeinfusst wird. Eine definitive Entscheidung zu geben wäre verfrübt." Meyer und v. Schweidler, loc. cit. p. 107.5.

+ The uranium nitrate under the experiments was obtained from Morek in Darmstadt and was labelled "extra pure."

I See Rutherford, 'Radionctivity,' p. $7 \mathrm{l} \&$ fig. 11. 
rays, recovered its activity according to a complementary curve*.

The only difference between my experiments and those of Neyer and Schweidler was that my uranium nitrate was deprived even of its water of crystallization by evaporation, while in the experiments of the above named authors the uranium nitrate was crystallized from the solution. This proves that the rapid decay of activity occurs only when uranium nitrate is crystallized, but it does not oceur when it was obtained from the solution by evaporation which had been carried so far that the water of crystallization was driven off.

This fact being established, the subsequent experiments were made in the same manner as the experiments of Meyer and Schweidler.

After separation of the ether solution, the aqueous solution containing an excess of UrX was concentrated on the waterbath, and was then left for a short time at the temperature of the room. The great part of the uranium nitrate crystallized at the bottom of the dish forming a compact plate, on the surface of which the rest of the solution remained. 'I'his mother liquor was poured off into another dish and was kept on the water-bath until the solution lost all except the water of crystallization. 'The solution after it was taken off the water-bath crystallized at the temperature of the room, forming a compact dry plate.

The whole process of preparation and measurement was repeated many times. Table I. gives one of the series of experiments. $\mathrm{T}$ denotes the time in days from separation to measurement. The $\beta$ activity is expressed as the ratio of the activity of the investigated product to the $\beta$ activity of a standard amount of uranium oxide taken as 1000 . The $\beta$ activity is expressed in the same units throughout this paper.

These results are graphically represented in fig. ], where the ordinates give the activity, in the same units as before, the abscissa the time in days after separation. Curve I gives the activity of the ether portion, curve II that of the first plate of crystal, curve III the activity of the plate of crystal obtained from the mother liquor.

* I omit the detailed numbers obtained in these measurements because the results are completely nornal ; and further, during the time when these investigations were being made Meyer and Schwoidler published $n$ short paper (Wiener. Sitzungsber. Dec. 1904) in which they showed that when a very small amount of water was present in the solution, the decay of activity of UrX was quite regular. 
TABLE I.

\begin{tabular}{|c|c|c|c|c|c|}
\hline \multicolumn{2}{|c|}{ Ether portion. } & \multicolumn{4}{|c|}{ Water portion. } \\
\hline & & First $c$ & ystal plate. & $\begin{array}{r}\text { Plate } \\
\text { from } \mathrm{u}\end{array}$ & $\begin{array}{l}\text { of crystal } \\
\text { ther liquor. }\end{array}$ \\
\hline $\mathrm{T}$ & B Aotivity. & $\mathrm{x}$ & $\beta$ Activity. & T. & $\beta$ Aotivity. \\
\hline $\begin{array}{l}0 \cdot 25 \\
1 \\
2 \\
3 \\
5 \cdot 3 \\
6 \cdot 3 \\
7 \cdot 3 \\
8 \cdot 3 \\
9 \cdot 3 \\
13 \cdot 3 \\
14 \cdot 3 \\
15 \cdot 3 \\
16 \cdot 5\end{array}$ & $\begin{array}{r}19 \\
57 \\
84 \\
131 \\
190 \\
220 \\
260 \\
273 \\
311 \\
420 \\
446 \\
460 \\
480\end{array}$ & $\begin{array}{r}0 \cdot 10 \\
0 \cdot 32 \\
075 \\
1 \cdot 12 \\
1 \cdot 64 \\
2 \cdot 9 \\
4 \cdot 9 \\
5 \cdot 9 \\
7 \cdot 0 \\
8 \cdot 1 \\
9 \cdot 1 \\
12 \cdot 8 \\
13 \cdot 8 \\
14 \cdot 8 \\
16 \cdot 4\end{array}$ & $\begin{array}{l}366 \\
281 \\
210 \\
219 \\
236 \\
285 \\
344 \\
368 \\
399 \\
427 \\
440 \\
529 \\
545 \\
572 \\
598\end{array}$ & $\begin{array}{c}0.12 \\
0.33 \\
0.75 \\
1.12 \\
1.68 \\
2.9 \\
4.9 \\
6.0 \\
7 \cdot 0 \\
8 \cdot 1 \\
9 \cdot 1 \\
12 \cdot 9 \\
13 \cdot 8 \\
15 \cdot 7 \\
18 \cdot 7\end{array}$ & $\begin{array}{l}2190 \\
1370 \\
1270 \\
1125 \\
1090 \\
1090 \\
1100 \\
1120 \\
1180 \\
1210 \\
1210 \\
1200 \\
1210 \\
1190 \\
1200\end{array}$ \\
\hline
\end{tabular}

It is seen that the activity of the ether portion increases with the time according to the theoretical curve, reaching half final value in twenty-two days. The activity of the first part of aqueous solution, which contained the first crystals, falls to about half value in about one day, this value being almost the minimum, and then increases slowly with the time. As we see from fig. 1, the second part of curve II is parallel to curve I, which shows that the activity of the first plate of crystal increases at the same rate as that of the ether portion.

The plate obtained from mother liquor (curve III) lost its activity during the first few days after crystallization. Its activity after raching a minimum and after a small increase remained practically constant. After two months it was observed to have decreased only 10 per cent.

Disregarding for a moment the first rapid decrease of activity of both aqueous portions, which is exactly of the same nature as observed by Meyer and Schweidler, we see that we have the $\beta$ activity in two cases increasing at the same rate, i.e. the increase of activity of the ether portion and of the plate of crystal first obtained. This points to the fact, that UrX was removed not only from the ether portion, but also in some degree from the first obtained crystals. Phil. Mag. S. 6. Vol. 10. No. 55. July 1905. 


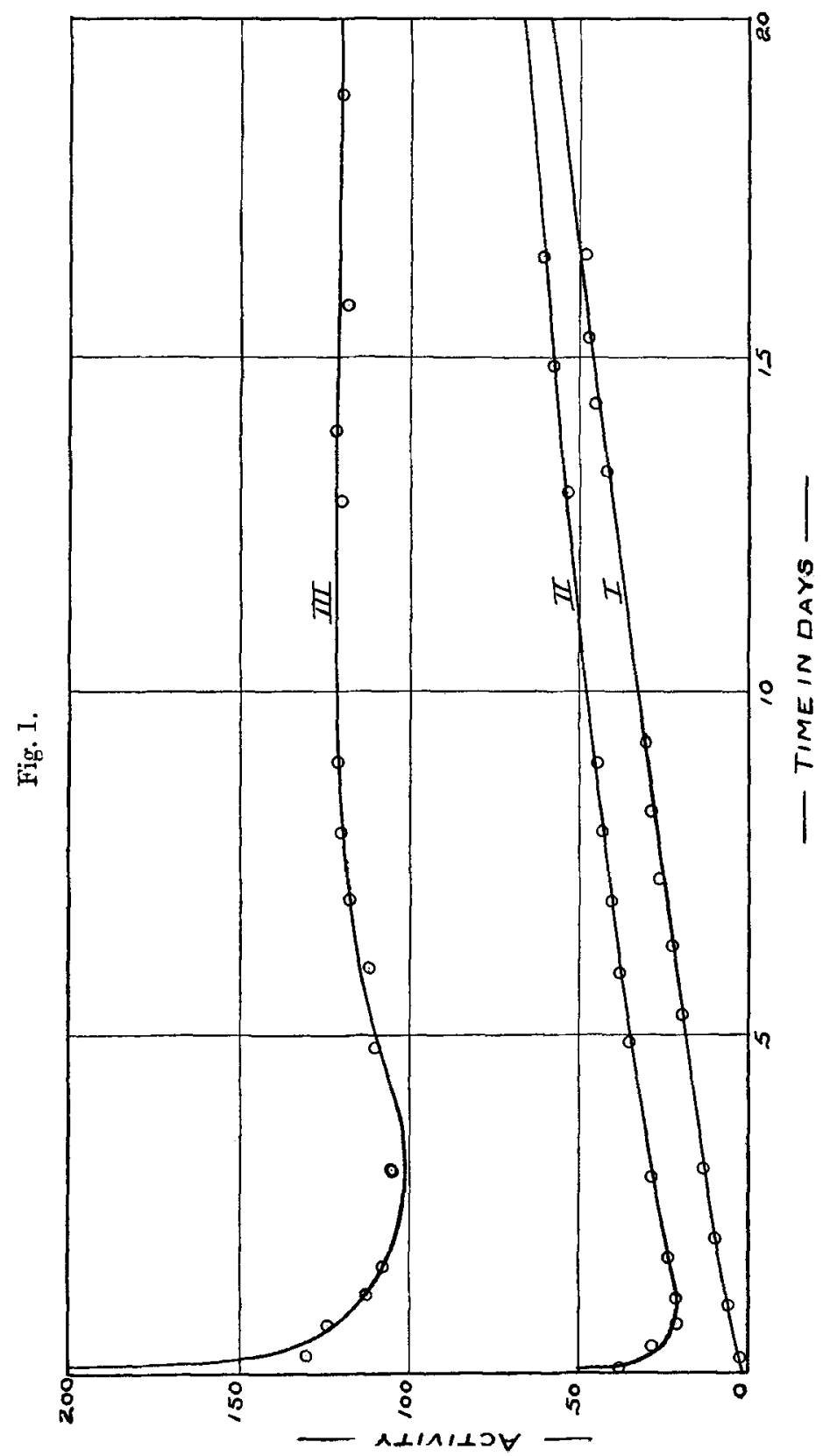


The mother liquor must contain then the greater excess of $\mathrm{UrX}$.

In connexion with this, experiments were made with fresh uranium nitrate, and they showed that by even one crystallization it is possible to separate the uranium nitrate into two parts, namely the crystals and the mother liquor; the latter part containing seven times as much of $\mathrm{UrX}$ as the former. By means of several fractional crystallizations we can deprive uranium almost completely of the substance $\mathrm{UrX}$, which is so readily soluble in water.

This at once explains the radioactive behaviour of the crystals first obtained from the aqueous solntion after treatment with ether. A large part of the $\mathrm{UrX}$ remained in the mother liquor, and the erystals themselves contained even less than the equilibrium amount of UrX. In consequence, the activity of the crystals must increase according to a recovery curve of UrX. The experiments show that this is really the case. (See curve II on fig 1.)

In a similar way we can equally well explain the increase of activity observed by Meyer and Schweidler* in the crystals of uranium nitrate obtained from water solution.

If in these experiments some part of mother liquor was poured off the surface of the plates of crystals, the uranium crystals would contain less of $\mathrm{UrX}$ than the uranium itself in a state of equilibrium. The increase of activity would thus be due to the recovery of the separated UrX. And in fact the authors state that this part of curve corresponds to the constant of 22 days.

The activity of the crystals obtained from the mother liquor at first decayed very rapidly and, after reaching a minimum, increased a very small amount and finally remained almost constant, falling only 10 per cent during two months. This is shown in curve III.

The percentage decrease observed in this experiment is smaller than the percentage rise observed in curves $I$ and $\Pi$. This is due to the fact that the layer of crystals finally obtained from the mother liquor was about three times as thick as in the previous fractions.

In other experiments, where the thickness of the plate was relatively very small, the excess of $\beta$ activity diminished regularly and in a more marked degree.

* Meyer and Schweidler, loc. cit. p. 1074, figs. o \& 7. 


\section{The Effect of Crystallization on the $\beta$ Activity of Uranium Nitrate.}

We shall return now to the initial rapid decay of the $\beta$ activity of uranium nitrate immediately after it was crystallized in the form of plates from the aqueous solution.

A decay quite analogous to that shown in the first part of the curves II and III was also obtained, when uranium nitrate had been crystallized from the pure aqueous solution, when no ether separation was applied.

The following is one example:-

25 grams of uranium nitrate was dissolved in a small amount of water ; the solution was evaporated on a waterbath till it lost all its excess of water. This solution of uranium nitrate in its water of crystallization was kept for some minutes at the temperature of the room, where it crystallized, forming a compact dry plate. The variation of activity with the time was then measured, and one of the examples is given in Table II., where $\mathrm{T}$ is time reckoned in hours from the moment of crystallization.

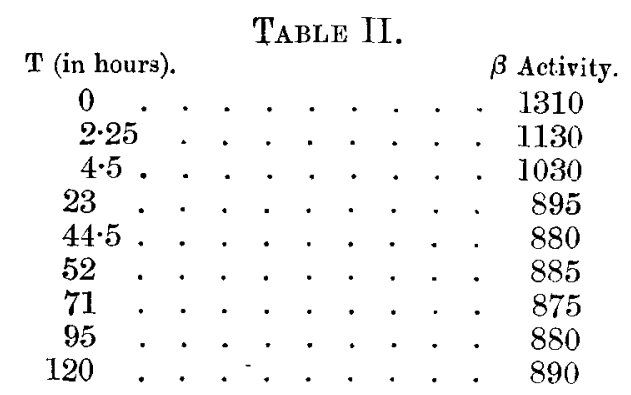

We see that immediately after crystallization the $\beta$ activity decays, reaching a minimum after about two days.

The measurements of Meyer and Schweidler were then once more confirmed. The face that the minimum was reached in a shorter time after crystallization in the experiments of the writer than in those of Meyer and Schweidler, is fully explained by the difference in experimental conditions which greatly influence this period.

This decay of activity after crystallization at first suggests the existence of some other product besides UrX. But the absence of the complementary recovery curve contradicts this supposition. And further, the rate of decay of radioactive products is generally independent of conditions. In these experiments, however, the time when the minimum was 
reached, as well as the form of the curve, was dependent upon many factors. In different experiments, the relative values of the activity at the minimum point and the rates of decay were dependent upon the thickness of the plate of crystals, and upon the concentration of the solution from which the crystals were obtained.

In consequence, it would be difficult to suppose the existence of some other product.

The supposition of Meyer and Schweidler * that the phenomena are produced by some changes in absorbing power of the plates of crystals cannot explain the observed fact, when we take into consideration that the activity measured by a rays does not exhibit the same behaviour. The experiments of Meyer and Schweidler showed that the $\alpha$ activity remained practically constant. The writer made also experiments which completely confirmed this fact. And every change in absorbing power of the plates would be, of course, first of all shown by variation of $\alpha$ activity. Since these results can neither be explained by the existence of a new product nor by a change in absorbing power, there remained the possibility that the process of crystallization alone influences the $\beta$ activity of uranium nitrate. In order to show whether this was really the case, the following experiments were undertaken.

The hot solution of uranium nitrate containing only the water of crystallization was put under the electroscope. After about two minutes the disturbance of the gold leaf, produced by the neighbourhood of the hot body, ceased, and it was then possible to investigate the effect due to the process of crystallization by measurements of the activity. The experiments showed that at the moment when the crystallization started, the $\beta$ activity commenced to increase very rapidly, reaching the maximum when the crystallization was finished.

The following is an example of the experimental results obtained. 25 grams of uranium nitrate were dissolved in some water and evaporated in a flat glass dish on a waterbath until it lost all the excess of water. The dish containing this hot solution of uranium nitrate in water of crystallization was then put under the electroscope. After three minutes the activity could be measured with accuracy. The results are shown in Table III., where $T$ is the time in minutes from the moment when the solution was taken off the water-bath.

* Meyer and Schweidler, loc. cit. p. 1075. 
TABLE III.

$$
\begin{aligned}
& \text { T (in minutes). Activity. } \\
& \text { 3... . . . . . } 900 \\
& 4.5 .5 .590 \\
& \text { 5... . . . . } 910 \\
& \text { 6........ . } 900
\end{aligned}
$$

At this period the crystallization started.

$$
\begin{aligned}
& \text { 8... . . . . . } 1000 \\
& 10 . . . . . . .1180 \\
& 12 . . . . . . . .1250 \\
& 14 \text {. . . . . . . } 1350 \\
& 17 . . . .5 . .51530 \\
& 22 \text {. . . . . . . } 1710 \\
& 27 \text {. . . . . . . . . } 1780
\end{aligned}
$$

At this period the crystallization ended.

$$
\begin{aligned}
& 30 \text {. . . . . . . } 1780
\end{aligned}
$$

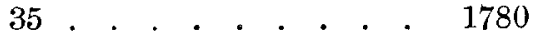

On the surface of the plate some drops of distilled water were now added, and the dish was placed again on the water-bath, so that the crystals melted in the water of crystallization. The measurements were repeated in the same manner as before.

In the moment when the second crystallization started, the activity of the solution was 1530 ; when it was finished the activity of the plate was 2830 .

After the third crystallization the activity was 2940.

The fourth and fifth and sixth crystallizations did not cause a further increase of the activity.

This maximum activity then decayed with the time and reached the value 935 after three days, and, disregarding small irregular oscillations, remained constant at this value through many weeks.

Similar experiments were repeatedly made, and gave the same qualitative results.

These experiments show that the $\beta$ actirity of uranium nitrate is very considerably angmented by the actual process of crystallization, and it will be proved later that the decay of activity noted immediately after crystallization is due to the loss of this excess of activity produced by crystallization.

The explanation of the increase of activity at the moment of erystallization is very simple. We know that all the $\beta$ activity of uranium proceeds not from the uranium itself, but from UrX. But UrX is so readily soluble in water that it is possible, as we have seen, to separate $\mathrm{UrX}$ from uranium by fractional crystallization. If, as usually the case, the hot 
uranium solution starts to crystaliize from the bottom of the dish, first of all uranium itself crystallizes and UrX is pushed in the direction of the surface. When the whole mass is solidified, we get a plate which contains on the surface an excess of $\mathrm{UrX}$, and in the lower layers a deficit of this substance. The $\beta$ rays, which come from the UrX present near the surface, emerge with little absorption in the mass of uranium itself, and thus the $\beta$ activity must be larger than when $\mathrm{Ur} \times$ is uniformly distributed throughout the plate. In the same way we can explain the steady growth of activity during the actual process of crystallization when UrX is continually passing to the upper layers.

Many observed experimental facts prove with certainty the correctness of this explanation of the increase of $\beta$ activity produced by crystallization.

For instance, we do not get the increase of $\beta$ activity when the solution is continuously stirred during the crystallization, so that instead of a compact plate there is a powder composed of very small crystals. Moreover, under suitable thermal conditions the crystallization may be started at the surface instead of at the bottom, and then the increase of activity is not observed after crystallization: but, on the contrary, there is often a decay.

This last fact suggested to me a decisive test. If the increase of activity during the crystallization is due to the fact that UrX is pushed to the upper layers when the crystallization starts from the bottom of the vessel, then the lower layers of the plate of crystal should contain less of UrX. In order to see whether this was really the case, I took a plate of crystal of which the $\beta$ activity was 1840 . The plate was cat across so that it could be removed from the dish, and it was then taken out and inverted so that the under surface faced the electroscope. The $\beta$ activity was found to be 528 .

This experiment shows quite clearly the truth of the explanation of the rise of activity during the process of crystallization. By the crystallization, UrX was pushed to the upper layers; when we turn the plate, the upper layers containing the excess of UrX are now underneath and, before reaching the electroscope, the $\beta$ rays, which start from $\mathrm{Ur}_{\mathrm{r}} \mathrm{X}$, must pass through the whole thickness of the plate whereby they are to a great extent absorbed. And for this reason the activity of the plate, when it was turned over, was only one-tbird of the activity measured from the upper side. 


\section{Diffusion of UrX.}

The results obtained in the preceding section can now be used to explain the first rapid decay of $\beta$ activity of uranium nitrate after crystallization from the water solution.

We saw that in the case when uranium nitrate was obtained by evaporation from the solution, and not br. crystallization, this first decay was not exhibited. Moreover, it was pointed out that when the hot solution was stirred during crystallization, no increase of activity at the end of the crystallization was observed. It must now be noted that in this case we did not get any decay after crystallization.

We see then that the first rapid decay is the decay of the excess of activity produced artificially by crystallization, when the latter caused the uneven distribution of $\mathrm{UrX}$ throughout the plate.

This suggests the probability that the decay of $\beta$ activity in the first days after crystallization is produced by the diffusion of UrX from the upper layers of the plate, where it was in greater concentration, to the lower, where its concentration is smaller. Thus, if we observe the decay of activity when the upper surface is turned to the electroscope, we should expect to see the analogous increase when the bottom of the plate faces the electroscope. Experiment showed this to be the case. Some of the experimental results are shown in Table IV., where $T$ gives the time reckoned in hours from the moment of crystallization.

\section{TABLE IV.}

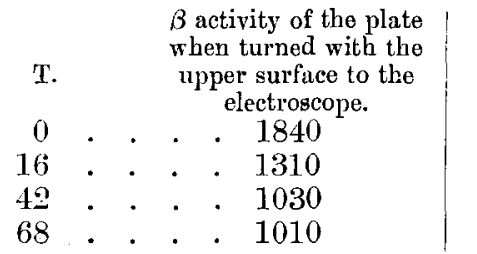

\begin{tabular}{|c|c|c|}
\hline & & $\begin{array}{l}\beta \text { activity of the plate } \\
\text { when turned with the }\end{array}$ \\
\hline T. & & $\begin{array}{l}\text { lower surface to the } \\
\text { electroscope. }\end{array}$ \\
\hline $0 \cdot 1$. & - & . . 528 \\
\hline 16 & & 747 \\
\hline 42 & & 731 \\
\hline & . & . . 950 \\
\hline
\end{tabular}

The same experiment made with a very thin plate.

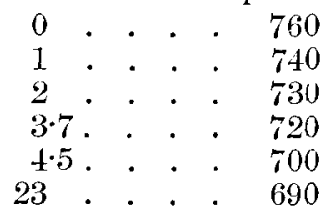

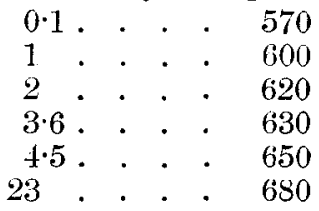

In order to completely establish that we here have to do with the diffusion of UrX through the plate from the layers 
of higher to lower concentration, the following experiment was made.

Fifty grams of uranium nitrate were treated with ether and from the remaining ether solution 15 grams were obtained consisting of uranium nitrate but almost completely freed from UrX. When the ether had been evaporated, some drops of nitric acid were added to the uranium nitrate and this was dissolved in hot water. The solution was evaporated till it lost all the excess of water, and then was kept at the temperature of the room for some minutes while it crystallized forming a dry plate of crystal. The $\beta$ activity of this plate measured 65.

In the other vessel $25 \mathrm{gr}$. of uranium nitrate were heated on the water-bath till it melted in its water of crystallization. This solution was then taken off the water-bath, and when the crystallization started $9 \mathrm{gr}$. of the hot solution were poured on the surface of the first plate of crystal. The solution crystallized then in a few minutes, forming the upper layer of the former plate.

In this manner a plate was made artificially which did not contain in the lower layersany UrX at all, but on the surface it did contain an excess of $\mathrm{UrX}$.

The plate was cut off from the dish and the activity from both surfaces was measured. The results are shown in the table, where $\mathrm{T}$ gives the time in hours after the crystallization.

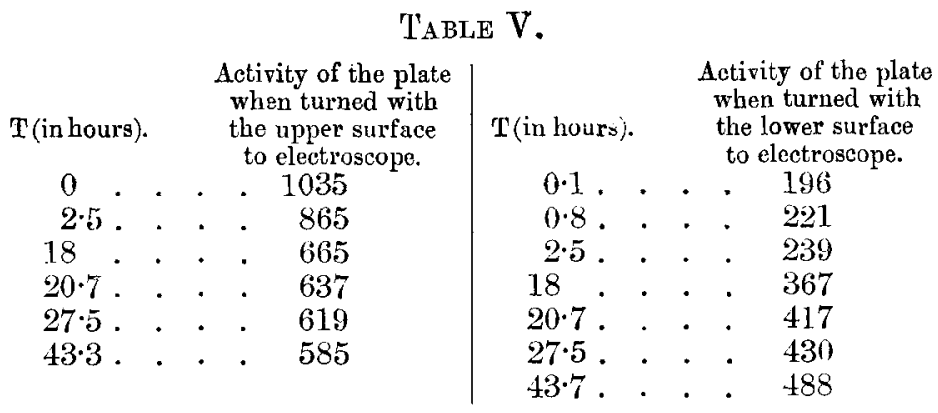

It is seen that the activity measured from the upper surface decreases, and that from the bottom surface increases, buth approximating to a common value.

This experiment shows that when we have a plate of crystal of uranium nitrate in which the substance $\mathrm{UrX}_{\mathrm{r}}$ is unequally distributed, UrX diffuses from the places where it is in higher concentration to places where its concentration is lower.

This diffusion of UrX therefore explains the first rapid 
decay after crystallization. We see also that the period during which the minimum activity is reached should depend on the thickness of the plate, and such is the case.

\section{The Possible Causes of the Diffusion.}

The question now arises, in what manner and under the influence of what forces does this diffusion take place? Only two explanations appear possible.

It may be supposed that some part of the $\mathrm{UrX}$ is dissolved in a small amount of water and diffuses in a state of solution between the crystals under the influence of capillary forces. The crystal plates under investigation, however, seemed to be completely dry ${ }^{*}$, and the diffusion took place even when a part of water of erystallization had escaped from the crystals on the surface. Therefore, the supposition that the UrX diffuses in the state of solution does not seem to be probable.

And if the diffusion does not take place under capillary forces, we are here dealing with a "solid solution." The crystals and the total mass of uranium are the solvent and UrX is the dissolved body. And then the UrX diffuses through the crystals from places of the higher to lower concentration.

We define the solution as a mixture of two substances, which is not a mechanical one, but is accompanied by the molecular penetration of both substances.

The process of formation of UrX points to the fact that we really have here a mixture of this kind. An atom of uranium, breaking up by expulsion of one $\alpha$ particle, changes into an atom of UrX, but it always remains surrounded by the other atoms and molecules of uranium. It is not possible to imagine the deeper molecular penetration as existing for the atoms which previously were the atoms of the parent body.

Throughout a given mass of uranium, single atoms of UrX are dispersed. Thus if we consider the total amount of $\mathrm{U} \cdot \mathrm{X}$ present at a given moment in a given quantity of uranium, we may assume that all this Ur $\bar{X}$ is "dissolved" in the uranium. The observed fact of the diffusion of UrX confirms this supposition. The diffusion of $\mathbf{U r X}$ goes in the direction from higher to lower concentration; we may

* Meyer and Schweidler, who first observed this decay of activity after crystallization, due, as we saw, to diffusion of UrX, pointed out that the plates investigated were completely dry (rollkommen trocken). Loc. cit. p. 1068. 
conjecture from higher to lower osmotic pressure. But this osnotic pressure, whilst it might control the diffusion, cannot be imagined as completely analogous to the osmotic pressure as known in fluid solutions. In the case of extremely weak concentration of $\mathrm{UrX}$, the ordinary osmotic pressure would be a vanishing quantity. But in the present case, the forces which guide the diffusion must be extremely great in order to overcome the immense resistance due to friction. These forces can only result from the reciprocal action between the molecules of the parent body and the atoms of its product, and appear to be a special radioactive type.

Just as UrX is dissolved in its parent uranium, so the other radioactive products should be dissolved in their parent. There are some experimental facts which confirm this supposition. We know that radium and thorium give ont a gaseous emanation as one of their successive products. The emanation is produced at a constant rate, which does not depend on any physical or chemical agencies, but the escape of the emanation from the body is variable in character and dependent on different conditions. For instance, radium and most of the compounds of thorium give off little emanation when in a solid state. The emanation is stored in the body itself in considerable amount. We may suppose that in reality just as UrX was dissolved in uranium, so the radium and thorium emanations are dissolved in radium and thorium.

When the parent body is dissolved, the emanation is no longer held bound in the solid solution, and it can readily escape from the water. And it is a fact that all substances have the maximum emanating power when dissolved. The increase of emanating power in presence of moisture can be explained in the same manner.

We know further that generally the solubilities of the gases decrease with the temperature. And indeed the emanating power of almost all radioartive bodies increases when the temperature is raised, reaching a maximum at a dull red heat. At this temperature the solubility should be a minitum and all the emanation should escape.

But the solubility of thorium emanation is not the same in all compounds of thorium. A compound like the hydroxide or carbonate possesses an equal emanating power in the solid state as in solution. This would indicate that thorium emanation, readily soluble in thorium nitrate and soluble in thorium oxide, is not soluble in thorium hydroxide or carbonate. We should then expect that in the last cases the emanating power should not be influenced by variation 
of temperature. The experiments of Rutherford and Soddy * show that this is the case.

The existence of "de-emanated" products after strong ignition whereby many physical and chemical properties of the compound are changed, can be also explained by the change in dissolving power of these compounds. Further investigations will show if this generalization of the fact observed in the case of uranium is justifiable.

Further experiments on this subject are in progress. Analogous experiments will also be tried with other radioactive products in order to see whether this explanntion is general.

In conclusion I wish to express my best thanks to Prof. Rutherford for the interest he took in this work and for the encouragement I received from him.

McGill University, Physics Building, April 3, 1905.

\section{The Boomerang. By J. W. Sharpe, M.A. $\dagger$}

$I^{1}$

$\mathrm{T}$ is easy to show in what manner the leading peculiarities of the boomerang's motion depend upon fundamental dynamical principles.

Though the instrument is not perfectly flat, it will be convenient to use the term "principal plane" for its average plane. The C.G. is somewhere within the concavity, and the two horns are symmetrically disposed with regard to it. The normal through the C.G. to the principal plane will be called the axis of the boomerang. The three principal axes of inertia at the C.G. are one along this axis (this one has the maximum moment of inertia), and two others in the principal plane, respectively parallel and perpendicular to the line joining the horns.

Imagine the boomerang held in the right hand, upright, with the concave edge forward and the principal plane vertical, which is in fact the ordinary posture for making a returning throw. The surfaces are both slightly convex, the one next the thrower (to be called throughout the motion the "upper" surface) being always the more curved one of the two. Also the whole instrument has a slight twist in it, so that the "upper" side of the upper horn and the "lower" side of the lower horn are slightly turned towards, and facing, the thrower. This twist is such as to make the boomerang serew itself upwards in the air when thrown with its principal plane horizontal instead of vertical. Its bent form has the

* Rutherford and Soddy, Phil. Mag. April 1903, p. 453.

$\dagger$ Communicated by the Author. 